\title{
La créolité et les Juifs de la Martinique
}

Caribbean hybridity and the Jews of Martinique

\section{William F.S. Miles}

Traducteur : Loïza Nellec-Miles

\section{(Q) OpenEdition}

\section{Journals}

Édition électronique

URL : http://journals.openedition.org/plc/823

DOI : $10.4000 /$ plc. 823

ISSN : 2117-5209

Éditeur

L'Harmattan

Édition imprimée

Date de publication : 1 janvier 2010

Pagination : 129-162

ISBN : 978-2-296-1141-3

ISSN : 1279-8657

\section{Référence électronique}

William F.S. Miles, «La créolité et les Juifs de la Martinique », Pouvoirs dans la Caraïbe [En ligne],

16 | 2010, mis en ligne le 22 septembre 2011, consulté le 30 avril 2019. URL : http://

journals.openedition.org/plc/823 ; DOI : 10.4000/plc.823 


\title{
LA CREOLITE ET LES JUIFS DE LA MARTINIQUE ${ }^{1}$
}

\author{
William F.S. MILES \\ Professeur de sciences politiques \\ Northeastern University, Boston USA \\ Traduit de l'américain par \\ Loïza NELLEC-MILES \\ Chargée de cours en Français \\ Northeastern University, Boston USA
}

\section{De Fanon à Confiant : l'incomplète créolité martiniquaise}

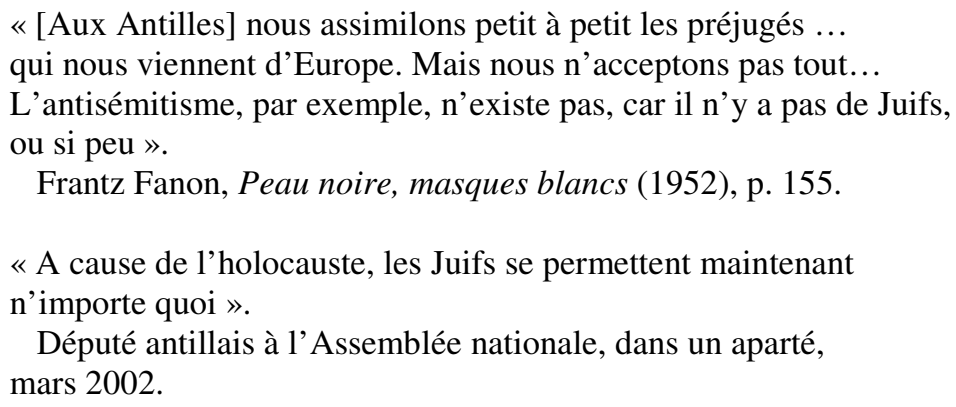

Entre l'antisémitisme fasciste tant redouté par Fanon et l'antisémitisme de gauche partagé par ce député - celui pour lequel la shoah est peu, comparée à l'esclavage - la Martinique a en effet bien changé. Nonobstant les liens éventuels entre Dieudonné et Jean-Marie Le Pen, l'affaire Dieudonné/Confiant de juin 2005 est un cas de figure révélateur. Elle a commencé en mars 2005 quand l'humoriste Dieudonné reçut quelques bonnes gifles des mains de jeunes Juifs qui avaient perçu certains de ses propos comme diffamatoires. Ces derniers furent condamnés à six mois de prison dont cinq avec sursis.

\footnotetext{
${ }^{1}$ Cet article a d'abord été rédigé pendant un séjour au Centre de Recherches sur les Pouvoirs Locaux dans la Caraïbe (CRPLC) à l'Université des Antilles-Guyane (Martinique) en février 2001 et publié en anglais, dans: Kristin Ruggiero (ed.). The Jewish Diaspora in Latin America and the Caribbean. Fragments of Memory. Brighton, R.U.: Sussex Academic Press, 2005. En 2007, encore au CRPLC, une mise à jour a été effectuée. L'auteur tient à remercier Justin Daniel, Adams Kwateh, Arlette Rosa-Lameynardie, Amram Riboh, Roger Toumson et, surtout, Roland Suvélor pour leurs suggestions, leur assistance, et leur grande perspicacité. Toute erreur m'incombe uniquement.
} 
Un an et demi plus tard, Raphaël Confiant pour parler de leurs coreligionnaires choisit de les désigner dans un essai diffusé par courrier électronique par le terme « les innommables ». Une polémique s'ensuivit qui s'est répandue jusque dans les colonnes du journal Le Monde.

Le fait qu'une communauté sépharade s'est bien réinstallée à la Martinique depuis l'époque de Frantz Fanon a peu à voir dans cette affaire : comme le notent des spécialistes du Japon à ce propos, l'existence d'une communauté juive n'est pas du tout nécessaire pour que l'antisémitisme fasse son apparition. Et le fait que les partisans du maître en onomastique, père du terme «innommables", ne sont ni représentatifs ni très suivis est aussi secondaire. Comme l'écrit Michel Giraud, qui se fait le vigile depuis un quart de siècle sur les dérapages identitaires aux Antilles, il ne faut pas prendre l'arbre d'un mot particulier, ou son parrain, pour « la forêt des crispations identitaires qui émaillent de plus en plus souvent les discours et les attitudes de certaines élites intellectuelles et politiques du monde antillais » (Giraud 2007 : 81). Pour lui, le signifiant se trouve dans le «réflexe» d'une identité qui est «excluante» et «exclusive» (ibid.). Il faut se garder du danger, propagé par le nationaliste aussi bien que par l'antisémite, de décider « du Mal », selon les termes de Sartre, "pour n'avoir pas a décider du Bien » (Giraud 2000 : 87).

Au-delà de la perspective tranchante de Michel Giraud, nous voulons souligner un autre paradoxe à ajouter à ceux que nous avons présentés antérieurement (Miles 1992) : le décalage entre le discours de la créolité dont le Pr. Confiant est l'un des porte-parole originaux - et la nonreconnaissance d'un constituant juif, établi et rétabli, sur l'île des Revenants.

\section{Créolité et diaspora}

Plus que toutes les autres îles françaises de la Caraïbe, la Martinique se vante de sa diversité, de son hybridité, de son métissage - bref, de sa créolité. Satisfaite autrefois de distinguer son identité par rapport à la métropole par le biais de l'héritage africain de la négritude, la Martinique d'aujourd'hui assume entièrement l'éventail des différents composants ethniques de son passé. En effet, outre les descendants d'esclaves, cette communauté réinventée, pour paraphraser Benedict Anderson, a fait assurément siens les éléments asiatiques, amérindiens, européens et syriens 
de sa population. Lesquels, par leur mélange, ont contribué à créer la Martinique bigarrée que nous connaissons. Cette créolité permet à la Martinique de revendiquer une place spécifique au sein de la République française.

Pourtant, une communauté reste exclue de cette image idéalisée que la collectivité martiniquaise a de soi : celle des Juifs. Les Juifs se sont établis à la Martinique - fût-ce de manière discontinue - depuis le début de son existence en tant que colonie française au XVII ${ }^{\mathrm{e}}$ siècle. Or, ceux-ci ne sont pas pris en compte dans l'image que la collectivité martiniquaise se forme d'elle-même. Chaque entité a sa part de responsabilité dans cette situation.

Les Martiniquais, bien que multiculturels sur le plan ethnique et racial, demeurent principalement chrétiens, surtout catholiques, sur celui de l'identité religieuse. Les Juifs, quant à eux, fondent leur réticence moins sur des divergences religieuses que sur un moindre sentiment d'enracinement dans le pays : après une trentaine d'années passées sur l'île, les Juifs ne se sentent toujours pas chez eux. Ils y sont installés, mais vivent en marge, sur la défensive, prêts à fuir les abords d'une société en laquelle, de manière parfois justifiée, ils n'ont pas entièrement confiance. Tant que la Martinique ne considérera pas la communauté juive comme une couche intégrante de son multiculturalisme identitaire, tant que les Juifs eux-mêmes ne surmonteront pas leur réticence à assumer la réalité de leur présence géographique, la créolité martiniquaise tant claironnée restera incomplète.

\section{Les premiers Juifs de la Martinique ${ }^{2}$}

L'on ignore trop souvent que des Juifs figurent parmi les tout premiers colons de la Martinique. Moins de trente ans, en effet, après que Belain d'Esnambuc eut pris possession de l'île au nom de la France, quelques Juifs hollandais fuyant le Brésil, à partir de Recife, principalement, après sa conquête par les Portugais en 1654, trouvèrent refuge dans la partie nord-est de la Martinique qui porte encore le nom de Petit-Brésil ${ }^{3}$. Bien qu'on leur

\footnotetext{
${ }^{2}$ Cette section s'appuie en grande partie sur les travaux de Loker (1991), Petitjean-Roget (1956), Riboh (5762-2002), et Roth (1932).

${ }^{3}$ Certains de ces réfugiés en provenance de Recife se sont retrouvés à la NouvelleAmsterdam, devenant les premiers Juifs de la ville qui s'appellera plus tard New York.
} 
doive l'introduction des techniques permettant la cristallisation et le raffinage du sucre - avec la construction des canaux d'irrigation et des moulins à eau et à vent, ces « anciens marranes ${ }^{4}$ » furent l'objet des persécutions officielles. En 1659, sous la pression des jésuites, le droit de commerce leur fut dénié ; en 1685, Louis XIV ordonna leur expulsion de l'île. Leur nombre ne dépassait pas quatre-vingts. Quelques-uns s'enfuirent vers la Barbade, d'autres devinrent conversos, c'est-à-dire chrétiens sous la contrainte.

Après cela, les Juifs restés à la Martinique s'épanouirent sur le plan économique, l'interdiction de commerce avait été modifiée ; les Juifs qui refusaient de pratiquer le commerce durant le shabbat étaient soumis à une amende. On pouvait mesurer leur richesse au nombre d'esclaves en leur possession : cent exactement. Ils étaient relativement libres de pratiquer leur religion :

Les Juifs qui sont établis ici emploient les samedis à faire leurs cérémonies, obligeant leurs nègres et engagés d'observer leur Sabbat et de travailler le dimanche et se montrent en public durant le deuil de l'Eglise qui dure depuis le Jeudi Saint jusqu'au dimanche de Pâques, contrairement à ce qui s'observe dans tous les milieux de l'Europe où on les tolère.

(Lettre du Gouverneur de Baas, le $1^{\text {er }}$ août 1669).

Cependant, encore une fois, dans les Caraïbes françaises comme en Europe, les Juifs eurent à subir le ressentiment de ceux qui voyaient dans leurs prouesses économiques une menace sur le commerce :

Je crois qu'il est nécessaire que le Roi envoie un règlement à l'égard des Juifs, ils ont des terres, des maisons en propre, ils ont des esclaves chrétiens, et quantité de commis chrétiens, ils font quasi tout le commerce, et se multiplient beaucoup, de sorte que le commerce est presque tout tenu par ces gens-là.

(Lettre au roi, 19 novembre 1680$)^{5}$

\footnotetext{
${ }^{4}$ L'expression est de Roth (1932), p. 229. Pour certains, le terme marranos est péjoratif. Le lecteur peut lui substituer celui de conversos.

${ }^{5}$ Réponse du 19 novembre au décret royal, citée par Zvi Loker. Jews in the Caribbean. Evidence on the history of the Jews in Caribbean zone in colonial times. Misgav Yerushalayim: Institute for research on the Sephardi and Oriental Jewish heritage, 1991. p. 199.
} 
En tête de ces premiers Juifs martiniquais figurent Jacob Gabaye, un résident de Saint-Pierre, la première capitale de la Martinique, sur la propriété duquel se trouvaient une synagogue rudimentaire et un cimetière juif ; Jacob Louis, de Rivière-Salée ; Abraham Bueno, du Marigot ; Isaac Le Tob, du Carbet ; et surtout Benjamin Da Costa, pionnier de la culture du cacao, de la canne à sucre et de l'extraction de l'indigo. Le chocolat et les confitures de fruits de Da Costa, préparés selon les recettes qu'il avait apprises des indigènes, les Indiens Caraïbes exterminés par la suite, étaient vendus à Amsterdam, Bordeaux et Bayonne. En introduisant le processus de raffinage du sucre à la Martinique, Da Costa allait changer le visage de l'île.

Or, ces Juifs n'étaient pas enfermés dans un ghetto ; la conscience des jésuites de l'île était à la torture :

Ils se mêlent impunément parmi les chrétiens, boivent et mangent avec eux et sous prétexte de trafic et de commerce abusent des personnes simples et corrompent l'innocence des femmes et des filles chrétiennes... Les enfants jouent indifféremment avec les enfants chrétiens.

(Lettre du 13 février 1683) ${ }^{6}$.

L'article 1 du fameux édit de mars 1685 , le document qui par ailleurs régularise la pratique de l'esclavage dans l'empire français, rend officiel l'ordre d'expulsion des Juifs promulgué par Louis XIV : «Enjoignons à tous nos officiers de chasser hors de nos Isles tous les Juifs qui y ont établi leur résidence auxquels comme aux ennemis du nom chrétiens nous commandons d'en sortir...»

Sur place, l'application des lois antijuives laissait plutôt à désirer : en 1695, la chancellerie française fit remontrance au gouverneur de la Martinique, le comte de Blénac pour avoir permis à six familles juives de rester sur l'île en lui rappelant «qu'il ne soit permis à aucun marchand, ou autre faisant profession de la religion juive de s'établir dans les îles et colonies françaises de l'Amérique... ${ }^{7}$. Il faut croire que le comte de Blénac s'empressa d'obéir à ce rappel à l'ordre et fit appliquer l'ordonnance antisémite de Sa Majesté.

${ }^{6}$ Cité par J. Petitjean-Roget, «Les Juifs à la Martinique sous l'Ancien Régime », Revue d'histoire des colonies, 1957, p. 150.

${ }^{7}$ Locker, op. cit, p. 203. 
Dès 1727 cependant, les Juifs réapparurent à la Martinique. Parmi eux se trouve, en1728, Abraham, âgé de vingt-deux ans, fils d'Antoine issu de l'éminente famille Gradis originaire de Bordeaux. Abraham travaillait en étroite collaboration avec son frère David en tant que représentant de la compagnie chargée d'approvisionner la Marine (surtout en rhum) et qui portera plus tard le nom des Gradis. Abraham, célibataire sans enfants, mourut à l'âge de trente-deux ans laissant un testament notarié par lequel il léguait ses biens à ses deux sœurs, célibataires elles aussi, Judith et Rebecca. Les autorités françaises annulèrent le testament; le trésor royal s'appropria l'héritage sous prétexte qu'un Juif n'avait aucun statut légal sur l'île .

La famille Gradis prospéra néanmoins en même temps que l'industrie sucrière. Leur plantation se trouvait à Basse-Pointe, sur la côte nord, tandis que la plantation de la famille Depaz, Lopes Depaz fit ses débuts comme courtier chez les Gradis, était établie près de Saint-Pierre ${ }^{9}$. En 1764, apparemment dans le but de régulariser son statut, «la communauté des marchands de la nation hébraïque demeurant tout en cette isle » supplia le roi d'autoriser leur résidence, la construction de leurs usines sucrières et la manufacture de leurs produits. Tacite ou officielle, l'autorisation royale fut semble-t-il accordée. Comme sucre des îles dans le café créole, les familles juives de l'Ancien Régime se fondirent graduellement dans la société antillaise. Certains, comme les Depaz, en s'assimilant, s'intégrèrent dans le cercle des «békés " ${ }^{10}$ comme est désignée l'aristocratie catholique blanche de l'île. D'autres, comme les Bueno (devenus Lebon) et les Lévy ${ }^{11}$, semblent avoir transmis leur nom à quelques noirs et métisses à qui les origines sémitiques de leurs ancêtres (probablement propriétaires d'esclaves)

\footnotetext{
${ }^{8}$ Judith et Rebecca vivaient elles-mêmes en France. L'affaire fut encore compliquée par le fait que l'un des beaux-frères d'Abraham, Cousteault, avocat au Parlement, se réclama de l'héritage sur la base de sa «différence de religion». En effet, l'une des soeurs avait épousé Cousteault après s'être convertie au christianisme.

${ }^{9}$ Une étoile de David orne encore l'entrée de l'habitation principale. Les origines de la famille Depaz remontent à la ville de Livourne, en Italie.

10 Jean François Depaz avait été formellement baptisé neuf ans avant son arrivée en 1770 (cf. Bruneau-Latouche et Cordiez 2002), mais comme la plupart des conversos, sa famille avait préservé certains éléments des coutumes et de la symbolique juives. Une autre famille de békés notoires, les (Wielle) de Reynal aurait aussi des origines juives.

${ }^{11}$ Après plusieurs rencontres et entretiens téléphoniques avec les deux douzaines de familles inscrites dans l'annuaire sous le nom Lévy, Levi ou Lévi, il appert qu'elles n'ont guère conscience des origines juives de leur patronyme.
} 
échappent complètement. Après l'éruption de la Montagne Pelée qui annihila Saint-Pierre en 1902, peu de traces subsistent de l'ancienne présence juive à la Martinique à l'exception unique des distilleries de la famille Meyer ${ }^{12}$. Il revint au régime collaborateur de Vichy de ranimer le spectre de l'antisémitisme sur une île comptant si peu de Juifs en son sein.

\section{La deuxième guerre mondiale}

Ayant été nommé par Georges Mandel, ministre des Colonies de la Troisième République, l'amiral Georges Robert, ${ }^{13}$ en septembre 1939 est arrivé à la Martinique en tant que «commandant en chef des forces maritimes de l'Atlantique Ouest ». La situation politique internationale étant dangereusement agitée, il avait déjà été prévu que l'amiral Robert deviendrait haut commissaire des Antilles et de la Guyane «si la situation l'exige». En effet, avec l'entrée en guerre de la France, Robert s'investit de ce pouvoir supplémentaire, tout en restant fidèle au gouvernement en exercice - qui, entretemps, s'était déplacé de Paris à Vichy. En juin 1940, l'amiral Robert prêtait serment au maréchal Pétain. De 1940 à 1943, la Martinique se trouva donc sous le régime de Vichy, et sous la férule de l'amiral Robert.

Secondé par le gouverneur Henri Bresolles puis (début 1941) par le gouverneur Yves Nicol, Robert s'empressa d'appliquer aux colonies les lois antisémites promulguées en France métropolitaine. Parmi les plus proches confidents de l'amiral se trouvait le Comte de Cérézy, décrit par les services

\footnotetext{
${ }^{12}$ Les Meyer sont arrivés à la Martinique en provenance du Danemark. Même au plus chaud de l'affaire Dreyfus, une étoile de David ornait les étiquettes sur lesquelles ils vantaient la haute qualité de leur rhum (entretien personnel avec Léo Elizabeth).

Les recherches généalogiques conduites par le couple Rossignol pour le centenaire de l'éruption de la Montagne Pelée, dans le cadre de l'aide apportée aux survivants de SaintPierre font surgir trois patronymes familiers : Lévy (Joseph, au Carbet et Léontine, au Marin), Gradis (Raoul, au nom de la compagnie à Bordeaux) et Depaz (Louis Alexandre Victor). La demande de ce dernier fut rejetée pour la raison que, bien qu'orphelin, il était «capable de subvenir à ses besoins ; en possession de ressources » (www.stpierre1902.org).

Apparemment, un petit nombre de familles juives sont arrivées sur l'île au début du XIX ${ }^{\mathrm{e}}$ siècle. L'une d'entre elles aurait établi le quartier Lowinski (ou Lowenski) à Rivière-Pilote tandis que toutes les autres se sont fondues dans la population générale (entretien personnel avec Christine Clément).

${ }^{13}$ Je dois à Roland Suvélor les précisions touchant au statut officiel de l'amiral Robert.
} 
d'espionnage britanniques à la Martinique comme «très antisémite ». Le comte aurait ordonné le rapatriement des éventuels réfugiés juifs en provenance d'Afrique du Nord et de France métropolitaine ${ }^{14}$. Parmi les intellectuels juifs qui passèrent par la Martinique durant cette période se trouvait Claude Lévy-Strauss. Le régime local ne vit dans l'anthropologue qu' « un judéo-franc-maçon à la solde des Américains ${ }^{15}$ ». Parmi les «passagers clandestins» placés sous internement administratif au camp militaire de Balata en tant qu' ' individus dangereux pour la défense nationale et la sécurité publique », se trouvaient un certain Abraham Weisz et un Lévi $^{16}$.

Jennings a démontré le rôle ambigu que la Martinique a joué face à un Vichy désireux de se débarrasser de ces Juifs. Jusqu'en 1942 le régime avait envisagé l'île des Revenants comme point de transit, de durée indéterminée, pour les Juifs et autres «indésirables» de la métropole. En effet, six navires, de croisière et de cargaison, ont fait la traversée entre Marseille et la Martinique, chargés de refugiés. La Martinique « représenta le dernier projet français d'émigration avant la shoah ${ }^{17}$.

Les lois antisémites de la France de Vichy furent reproduites dans le Journal officiel de la Martinique (JOM). Par suite des « lois concernant le statut des Juifs » publiées dans le JOM du 26 octobre 1940, 236 déclarations de «non appartenance à la race juive » font maintenant partie des Archives Nationales (réf. M 4612). L'on peut aussi trouver un dossier intitulé «agents suspects » dans lequel un câble en provenance du cabinet du gouverneur, en date du 10 décembre 1940, fait référence à la «discrète surveillance » exercée sur deux fonctionnaires soupçonnés d'être Juifs : un certain professeur Salanski et un autre Jean Kehrig. Les dossiers contiennent aussi

\footnotetext{
${ }^{14}$ Cf. Richard D. E.Burton. "Vichysme et Vichystes à la Martinique », premier volume des Cahiers du CERAG dédié à La Martinique sous l'amiral Robert, 1978. p. 17 et note 81 (p. 30). ${ }^{15}$ Cet extrait provient du journal anti-Vichy Tristes Tropiques cité tel quel par Fitz A. Baptiste dans «Le Régime de Vichy en Martinique : l'Application des Mesures d'Ordre Public», second volume des Cahiers du CERAG consacré à La Martinique sous l'amiral Robert, 1979. p. 71 .

${ }_{16}$ Journal Officiel de la Martinique, 18 janvier 1941. Actes du Gouvernement Local, $\mathrm{n}^{\circ} 41$. Décision portant sur internement administratif.

${ }^{17}$ Traduction de l'auteur. Eric Jennings. «Last exit from Vichy France : the Martinique escape route... ». The Journal of Modern History, 2002, p. 324.
} 
les déclarations d'un Guthman ${ }^{18}$, nom suspect aux yeux de Vichy, attestant du caractère purement catholique de ses origines, de son éducation et de son mariage.

Deux documents attestent de la présence - dûment cataloguée par les autorités coloniales de Vichy - des Juifs sur l'île. Une liste du $1^{\text {er }}$ août 1941 constituée à partir des déclarations obligatoires (JOM du 28 juin 1941, p. 697- 699) et signée par le capitaine de gendarmerie Delpech contient les noms de vingt-deux adultes juifs (dont quatre femmes) plus celui d'une nonjuive mariée à un Juif (leur enfant est donc compté comme juif). Pour ces vingt-trois adultes ${ }^{19}$, la liste dénombre quatorze époux (cinq d'entre eux nonjuifs) et vingt-sept enfants (trois d'entre eux non-juifs). Parmi les vingt-deux adultes Juifs, le décompte des nationalités donne quatorze Français, trois Roumains, deux Algériens, un Belge, un Turc, et un «Palestinien ». De ce total de cinquante-cinq personnes enregistrées comme juives par les autorités françaises, treize (principalement les familles des Algériens Joseph Mishkal et Abba Simon Abadi, repartis en Palestine) étaient absentes. Trois mois plus tard (selon la lettre du capitaine Delpech du 21 novembre 1941), après le départ de la famille Steiner, de madame Raymonde Hayman (femme d'un conseiller à la Cour non-juif) et de Henri Halphen, la population juive résidant à la Martinique était réduite à trente-six membres. Dix des chefs de famille restants étaient des marchands (principalement de tissus). Parmi ceux-ci, on peut compter et identifier (par extrapolation à partir de la liste du $1^{\text {er }}$ août) deux photographes (dont Germaine Gold ${ }^{20}$, veuve, 36 ans), un médecin (Paul Stern, 31 ans), un employé de banque (Louis Sussfeld ${ }^{21}$ ), Aba

\footnotetext{
${ }^{18}$ Les autorités de Vichy avaient raison de soupçonner Guthman - mais pour des motifs tout différents : son nom figure plus tard dans un rapport de police sur les participants à la manifestation gaulliste (c'est-à-dire pour la France Libre ) du 18 juin 1943, à Saint-Pierre. Rapport de police de la Commune du Carbet (Léotin, 1993, p. 101). Le 28 juin 1943, le Comité Martiniquais de Libération Nationale fomenta un soulèvement forçant l'amiral Robert à quitter la Martinique, le 15 juillet.

${ }^{19}$ Il se trouve que c'est là le nombre exact de familles juives recensées en 1683 , sur l'ordre des persécuteurs jésuites. En 1683, la population totale de la Martinique était de 14000 habitants ; en 1941 elle s'élevait à 220 000. Données pour 1683 fournies par Chauleau (1990).

${ }^{20}$ Incapable d'exercer son métier, faute du matériel nécessaire, à cause du blocus imposé par la marine américaine, madame Gold s'est lancée dans la mercerie (entretien personnel avec M. Calvy, 9 mai 2002).

${ }^{21}$ Après la guerre cependant, Sussfeld devait témoigner en faveur de l'amiral Robert. Sans être nommément cité, c'est sans doute lui l'« Israélite » mentionné par Zizine, 1947, p. 10.
} 
Simon Abadi, un capitaine au long cours (Raymond Sazias, 39 ans), un entrepreneur en bâtiment (Jacques Kalfon, 44 ans), et un marchand (Fortuné Danon, 48 ans). Le seul professeur d'origine juive avérée à la Martinique, Ilijah (Elijah) Salanski, 30 ans, avait été chassé de son poste ${ }^{22}$. Sarah Lazareff, femme de l'éminent fondateur des distilleries Clément, figurait aussi sur la liste ${ }^{23}$. De ces Juifs, trois seulement sont restés à la Martinique après la guerre et y ont laissé des descendants. Ces trois exceptions sont les Lazareff, Kalfon et Danon (les deux premiers avaient épousé des non-juifs). Leurs enfants sont tous complètement créoles ${ }^{24}$.

Sur la liste du Capitaine Delpech du $1^{\text {er }}$ août, Arnold Lato (25 ans) est enregistré comme soldat ayant précédemment servi en Guyane française, et Daniel Stern comme photographe. Il semble cependant que le scribe a inversé les données, à juger d'après ce que E. Jennings a découvert :

Daniel Stern, Juif français né à Caen et âgé de 23 ans, fut expulsé de l'armée française en Martinique en application rigoureuse des lois antisémites de Vichy ; il se reconvertit dans l'hôtellerie à Fort-de-France. Le 9 janvier 1942, il essaya de rejoindre une île anglaise voisine mais [la] tentative échoua au large de l'Anse Madame. [Il fut] alors dénoncé à la police... Sans la moindre procédure judicaire, Stern fut sanctionné et refoulé vers la

\footnotetext{
${ }^{22}$ Lors d'une entrevue avec l'auteur, le 25 avril 2002, Aimé Césaire s'est souvenu du professeur Salanski comme d' «un éminent mathématicien », qui avait enseigné au lycée Schoelcher et qui put éventuellement réintégrer l'Education nationale après la guerre. Dans l'intervalle, Salanski avait été embauché comme employé par le Père Droch, directeur du séminaire-collège de la Martinique.

${ }^{23}$ La mère de Mme Lazareff fut arrêtée à Paris et déportée à Auschwitz où elle mourut. L'une des enfants Clément-Lazareff raconte que, selon l'histoire de la famille, leur mère Sarah se serait présentée d'elle-même aux autorités de Vichy à la Martinique ; malgré les protestations des agents, elle aurait demandé «par solidarité avec les autres Juifs » d'être enregistrée comme juive et de porter l'étoile jaune. Il n'existe aucune preuve cependant qu'à la Martinique, les Juifs aient effectivement eu à porter l'étoile jaune.

${ }^{24}$ Un quatrième couple, celui des Bercovici - du « Magasin Maïer » comme ils étaient connus - mourut sans enfant. La liste de ces Juifs déclarés fut partiellement reproduite dans le texte d'une épreuve du brevet national, en juin 2002 à la Martinique. Les élèves devaient décrire le Régime de Vichy et son application aux Antilles. C'est là une reconnaissance assez rare de la présence juive (et d'une législation antisémite) dans le cadre de l'historiographie officielle martiniquaise.
} 
métropole, où l'attendait sans doute un sort autrement plus difficile ${ }^{25}$.

Dans le quartier populaire des Terres-Sainville, aux abords de l'église Saint-Antoine et du siège du Parti Communiste Martiniquais, se trouve une plaque où l'on peut lire :

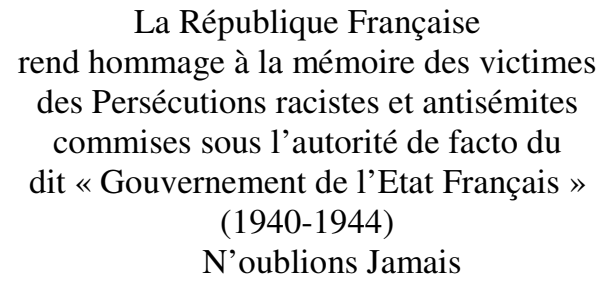

Face à ce monument, le 16 juillet de chaque année, les représentants du gouvernement français, de la municipalité de Fort-de-France et de la communauté juive procèdent à un dépôt de gerbes en commémoration de la rafle du Vel d'hiv. Une cérémonie du même genre se tient, chaque année, en avril, aux pieds du monument aux morts, un site plus connu, plus ancien et plus central, le long du front de mer, «à la mémoire des victimes et héros de la Déportation ».

\section{Renouveau de la présence juive et A.C.I.M.}

Les années 1970 ont vu la renaissance de la présence juive à la Martinique, conséquence à retardement de la guerre d'Algérie qui s'était terminée en 1962. Considérés comme citoyens français en vertu du décret Crémieux de 1870, les Juifs d'Algérie furent obligés de quitter ce pays au moment de son indépendance. Un petit nombre de ceux qui s'étaient installés en France se sentant mal à l'aise et insatisfaits, pensèrent trouver aux Antilles un terroir plus semblable à la Méditerranée de leurs souvenirs, un mode de vie plus agréable que celui de Marseille où d'autres avaient refait leur vie. Il faut dire que le climat n'était pas la moindre raison de cette attirance. Jeunes et aventureux, ils se sont établis dans le porte-à-porte, représentants en articles de literie (draps et matelas), en appareils ménagers (y compris

\footnotetext{
${ }^{25}$ Eric T. Jennings. «La dissidence aux Antilles (1940-1943)», Vingtième Siècle. Revue d'histoire, $\mathrm{n}^{\circ} 68$, octobre-décembre 2000, p. 55-72.
} 
télévisions), en bijouterie et en ameublement. En offrant leurs propres services de paiement et de crédit aux familles des bourgades rurales qui n'avaient pas accès à des services bancaires, ces jeunes marchands juifs servirent d'intermédiaires aux consommateurs de l'économie moderne.

Sans se considérer comme vraiment religieux, ces nouveaux arrivants juifs s'efforcèrent cependant de préserver les éléments fondamentaux de la tradition juive. Au début, ils célébraient les services religieux des grandes fêtes chez les uns ou les autres, jusqu'à ce que le manque d'espace les forçât à louer un local dans un hôtel. Un boucher en provenance de Tibériade traversait l'atlantique pour pratiquer le rituel de l'abattage casher.

En 1976, l'association cultuelle israélite de la Martinique (A.C.I.M.) fut officiellement formée et enregistrée auprès de la préfecture. Jusqu'en 1979, une maison aux Terres-Sainville à Fort-de-France servait de synagogue, puis elle fut remplacée par une autre au plateau Fofo, à Schoelcher. Lors des grandes fêtes ou des célébrations sacramentelles comme les mariages, les bar-mitzvas, ou les funérailles, ils faisaient venir un rabin de Caracas. Les viandes cashères venaient aussi du Venezuela. Même la Mimouna, cette fête spécifiquement sépharade qui marque la fin de la Pâque, vint à être célébrée à la Martinique.

En février 1996, la communauté franchit un pas majeur, marquant son ancrage sur l'île, avec l'inauguration de sa nouvelle synagogue, Kenaf Aaretz (lit. « les ailes » [c-à-d les antipodes] de la terre ») à l'anse Gouraud, dans la commune de Schoelcher. De hauts représentants des autorités nationales et locales, de l'Eglise, de l'armée et des communautés civiles (y compris la communauté palestinienne locale) étaient présents. Sont venus spécialement de Paris pour présider la cérémonie Jean Kahn, président du Consistoire central des institutions juives de France et le Grand rabbin de France en exercice à l'époque, Joseph Sitruk. Le comité d'action de la communauté de Kenaf Aaretz offre des classes d'instruction religieuse, entretient un mikveh (bain rituel) pour les femmes, vend les produits casher (viandes et vins), publie une gazette mensuelle et utilise les services d'un rabbin à plein temps. L'on peut trouver dans la capitale deux restaurants casher (dont l'un se double d'une boulangerie qui vend la challa, le pain tressé du shabbat). L'on peut aussi trouver dans les rayons des grands supermarchés un éventail de produits estampillés casher. Dans l'attente d'un permis de la part de la municipalité autorisant une section proprement juive, 
le cimetière des Hauts de Terreville à Schoelcher offre un mausolée où sont ensevelis les quelques Juifs décédés sur l'île ${ }^{26}$.

\section{Profil démographique et institutionnel des Juifs de la Martinique}

La population juive martiniquaise s'élève approximativement à 450 individus regroupés en 190 foyers $^{27}$. A peu près 280 des adultes sont membres officiels de l'A.C.I.M. Dans la plus grande majorité, ce sont des Sépharades d'Afrique du nord, principalement d'Algérie ${ }^{28}$ : Les piliers de la communauté sont issus des familles Chicheportiche, Illouz, Marciano, Nakache, Taëb, Zaoui, Zerbib. Le commerce - par exemple la vente de produits en aluminium (fenêtres sécurisées, portes) - est l'activité principale. Sans être particulièrement aisés - comme l'indiquerait l'achat d'une maison secondaire - ils vivent confortablement et de temps en temps, les mieux assis se cotisent pour fournir le billet d'avion nécessaire au rapatriement d'un compatriote tombé dans le besoin.

Bien que le chiffre de la population martiniquaise ait augmenté de plus de 50000 individus durant les deux dernières décennies pour atteindre le chiffre de 388000 de nos jours, le nombre de Juifs résidant sur l'île est resté stable. Cela reflète la grande mobilité des Juifs de la Martinique.

Mais qui est juif ? Comme dans le reste du monde juif, c'est une des grandes préoccupations de la communauté juive de la Martinique. Vingt-huit pour cent, tel est le pourcentage de la communauté que l'on peut définir comme mixte, c'est-à-dire engagé dans une relation, ou en est le produit, où l'un des partenaires est juif et l'autre non-juif ${ }^{29}$. C'est là une situation courante au sein de toute la diaspora, mais le fait prend un caractère un peu plus « épicé » en contexte, manifestant en quelque sorte une créolisation des mœurs en milieu antillais.

\footnotetext{
${ }^{26}$ Le premier Juif enterré à la Martinique récemment était un bébé de trois mois, fils de la famille Nahon qui mourut vers le milieu des années 1970.

${ }^{27} \mathrm{Ce}$ sont là les données compilées par l'A.C.I.M.. Sont inclus à la fois les Juifs se reconnaissant comme tels par les contacts qu'ils maintiennent activement avec la communauté juive et ceux qui sont connus comme tels par ouï-dire. La communauté ignore complètement le nombre des Juifs (principalement Ashkénazes) qui ne donnent pas signe de leur existence.

${ }^{28}$ La ville de Sétif est particulièrement bien représentée.

${ }^{29}$ Chiffres fournis par le rabbin en résidence.
} 
Il n'existe aucun test religieux pour faire partie de l'A.C.I.M. ou pour participer à ses activités - le paiement des frais d'inscription suffit. L'on peut ainsi être un membre officiel de la communauté "israélite », vivre comme un Juif (et même manger comme un Juif à la cantine casher qui sert les repas de midi à trois douzaines d'écoliers et le repas communautaire chaque shabbat), sans être vraiment juif d'après la halacha (la loi juive orthodoxe). Une telle ambigüité peut durer des années. Face à un obstacle du domaine sacramentel - circoncision, bar-mitzvah ou mariage - cette ambiguïté peut conduire à des situations parfois désagréables.

L'on peut mettre sur le compte de différences culturelles le fossé qui sépare la minorité ashkénase française originaire d'Europe de l'Est des Sépharades français d'Afrique du nord. Ces derniers, ayant été moins assimilés par le biais de l'éducation séculaire, sont de ce fait moins confortables en contexte non-juif. Des tentatives d'élargir et de moderniser les diverses approches de l'étude et de la culture juives - par exemple à travers l'ouverture d'un chapitre local de B'nai Brith - ont échoué face à l'incompréhension générale et à leur propre réticence, elle-même teintée de méfiance.

Une partie des tensions intra-sémitiques repose en effet sur la question des mariages mixtes. La plupart des adultes ashkénases sont entrés dans de telles unions, mais peu d'efforts ont été entrepris pour les intégrer dans la vie de la communauté. Pour la première fois, en 2002, l'A.C.I.M. a inclus la commémoration de Yom HaShoah dans son programme. Pour les Juifs d'origine européenne cette ignorance de l'holocauste refléterait moins un rejet délibéré qu'un manque de sensibilité communautaire et la tendance des sépharades à considérer la shoah comme une préoccupation principalement ashkénaze ${ }^{30}$.

Christine Clément, psychothérapeute pratiquant sur l'île, a décelé les symptômes du Syndrome Répressif de la Shoah chez une poignée de jeunes à la Martinique. Les petits enfants d'anciens déportés souffrent du silence et de la douleur internalisée transmis après l'holocauste à travers les générations. Issus de mariages mixtes antillais-juifs, perçus comme un moyen de couper

\footnotetext{
${ }^{30}$ Parmi les familles juives de la Martinique ayant perdu des proches dans la tourmente de la shoah (et qui avaient été invitées à allumer les bougies commémoratives) se trouvait l'un de ces rares couples « mixtes » ashkénaze-sépharade.
} 
tout lien avec leur judéité ${ }^{31}$, ces jeunes n'ont aucun rapport formel ou affectif avec la communauté juive. Bien qu'elle n'atteigne qu'un nombre relativement restreint d'enfants, la violence inexprimée de l'holocauste serait donc partie intégrante des troubles de la jeunesse qui affectent la société martiniquaise.

L'union formelle entre un homme juif et une femme antillaise, la plupart du temps dans ce sens prend parfois une orientation judéo-créole plutôt positive. Issus d'un milieu intrinsèquement plus spirituel que celui de la moyenne métropolitaine, les Antillais embrassent leur conversion au judaïsme de manière plus profonde en comparaison avec ce que l'on observe en métropole. Pour la mariée martiniquaise, la conversion au judaïsme va au delà d'une simple formalité. En tout cas, sanctionnées ou non par un mariage juif, peu à peu au cours des trois dernières décennies, les unions antillojuives ont certainement donné « un peu de couleur » à la communauté juive de la Martinique.

La question «qui est juif ? » se pose à la Martinique comme dans le reste du monde en général, mais la question « qui est juif martiniquais? » est plus spécifique. C'est aussi une question plus large et plus complexe étant donnée la nature déjà ambivalente de l'identité martiniquaise.

Les quelques Antillais qui se sont convertis au judaïsme étant évidemment martiniquais, qu'en est-il des familles juives qui ont vécu pendant plusieurs décennies sur l'île ? Ces Juifs, nés en Afrique du nord, émigrés en France qui ont fini par s'installer à la Martinique ne vont certainement pas se sentir martiniquais. Considérons le témoignage de cette femme sépharade nouvellement arrivée qui a trouvé à enseigner à l'école hébraïque :

C'était le premier jour de classe et les enfants parlaient bizarrement. C'était si nouveau pour moi que je ne savais pas que c'était du créole ou ce qu'était le créole. Quand j'ai essayé de comprendre et de corriger les élèves, ils se sont rebellés : «On est Juifs martiniquais, ici, madame. On n'est pas Juifs français!»

\footnotetext{
${ }^{31}$ Entretien personnel. Christine Clément est très sensible au phénomène de l'identité juive cachée : elle avait déjà atteint l'âge adulte lorsqu'elle découvrit que sa mère (française, fille d'immigrés algériens) était juive, convertie au catholicisme après la seconde guerre mondiale. C'est à la Martinique que cette psychothérapeute a fini par recouvrer son identité juive.
} 
Et pourtant, les békés, les descendants blancs créolophones des premiers colons des dix-septième et dix-huitième siècles, sont universellement considérés sur l'île comme martiniquais par les habitants «de couleur ». En outre, être martiniquais signifie aussi populairement - sauf pour les indépendantistes - être français (d'outre-mer). Pour les Antillais, une chose est sûre : ils ne sont pas des métropolitains. Le Juif né sur le sol martiniquais lui, considère qu'il appartient à la minorité sépharade de la France. L'immigrant juif d'Afrique du nord est-il français au même degré que le noir antillais?

Du fait que la Martinique est française, l'A.C.I.M. tombe sous la juridiction très orthodoxe et très conservatrice du Consistoire de Paris. Toutes les questions liées aux conversions ou aux statuts religieux sont donc résolues à huit mille kilomètres de la Martinique. Un mouvement messianique rival, celui des Loubavitch, a cependant fait une percée aux Antilles et dans d'autres départements et territoires d'outre-mer français. Basée à Londres, leur organisation (Ufaratsta) publie un journal, l'Hebdomadaire juif des Iles, qu'elle distribue aux synagogues de la Guadeloupe, Tahiti, la Réunion et la Nouvelle-Calédonie.

\section{Les images du Juif dans la société martiniquaise}

Il existe un grand fossé entre l'intelligentsia martiniquaise et les couches populaires en général en ce qui concerne l'image du Juif. Le Martiniquais moyen confère la même identité à tous les résidents originaires du Moyen-Orient, qu'ils soient musulmans de Palestine ou Juifs d'Afrique du nord : ce sont tous des «Syriens ». Même la kippah (la calotte juive) que beaucoup de membres portent en public maintenant n'arrive pas à projeter leur différence d'identité. Un marchand juif rapporte qu'au cours d'une conversation avec son médecin antillais sur les événements entre Israël et la Palestine, ce dernier, à la vue de sa kippah, l'avait pris pour un arabe propalestinien.

Vers le milieu des années soixante-dix, les activités de quelques personnages douteux ont fâcheusement terni l'image de la communauté. Ces représentants indélicats profitèrent de la naïveté et de l'ignorance des habitants de la campagne en leur vendant des appareils ménagers coûteux alors que ceux-ci n'avaient pas encore l'électricité. Les frères Zemmour, des 
Juifs algériens fameux dans la pègre française et nord-africaine pour leur racket et autres exploits mafieux, ont fait un bref mais inoubliable passage à la Martinique. Il faut se rappeler que vers la fin des années soixante-dix, pour les Français en mal d'aventures, les Antilles représentaient encore une sorte de Wild West, une frontière tropicale sans les contraintes et les carcans qu'ils rencontraient en Métropole. Certains gros bras sépharades sont arrivés sur l'île avec leur réputation douteuse - et leurs révolvers. Tandis que la majorité observait le shabbat à la synagogue, certains le passaient en prison.

Et pourtant, dans les campagnes et pour les Martiniquais avec un tant soit peu d'instruction religieuse, le Juif évoque d'abord le Juif du Nouveau Testament, le Juif habitant de l'antique terre de Palestine. Même Aimé Césaire, l'intellectuel martiniquais par excellence, lors d'un entretien avec l'auteur, avançait : «Jésus Christ était Palestinien, n'est-ce pas ? Quelle différence y a-t-il entre un Palestinien et un Juif ? »

Césaire a en fait été le premier Martiniquais à restituer au Juif la place qui lui revient dans la formation de l'identité antillaise moderne. Dans son fameux poème épique Cahier d'un retour au pays natal (1947) fondation littéraire de la Négritude - Césaire évoque de manière très vivante le Juif, victime (blanche) du racisme :

L'homme-famine, l'homme-insulte, l'homme-torture on pouvait à

n'importe quel moment le saisir le rouer de coups, le tuer -

parfaitement le tuer - sans avoir de comptes à rendre à personne

sans avoir d'excuses à présenter à personne

un homme-juif

un homme-pogrom

un chiot

un mendigot.

En 1956, dans son discours en l'honneur de l'abbé Grégoire, abolitionniste du dix-huitième siècle, Césaire remarquait que les préoccupations antérieures de Grégoire avaient été consacrées à la sauvegarde de Juifs en France. «C'est comme s'il était naturellement passé du ghetto du Juif à la case de l'esclave ».

Quarante ans après sa publication, le passage du Retour au pays natal cité ci-dessus figurait en première place d'une exposition itinérante de l'UNESCO sur Césaire ; en 1998, celle-ci se produisit à la Martinique. Son catalogue était encore plus explicite sur la référence aux Juifs : 
Le nègre est aussi le Juif, l'étranger, l'amérindien, l'analphabète, l'intouchable, celui qui est différent... bref, celui qui par son existence est menacé, exclu, marginalisé, sacrifié.

«Ce n'est pas que je sois spécialement pour les Israéliens », dit cet homme qui parle si chaudement du Juif de la shoah, «mais il est nécessaire de mettre les choses au point. Ce n'est pas le racisme qui les motive mais le nationalisme. Ce n'est pas la même chose... Les racines sont historiques, pas raciales... Les Israéliens ont l'impression que l'Etat qui était un tel défi à bâtir - et il est jeune, après tout - est en jeu. La motivation essentielle d'Israël est sa volonté d'exister. Il est angoissé de voir son avenir menacé » ${ }^{32}$.

Aimé Césaire a littéralement planté le signe le plus visible d'une présence «juive» aux Terres-Sainville, au coeur du ghetto de Fort-deFrance. Au milieu du square qui porte le nom de l'abbé Grégoire, Césaire a planté ce qui est devenu un énorme arbre parasol : un Enterolobium cyclocarpium, pour l'érudit ; «oreille de Juif»; «oreille de noir» pour l'homme de la rue ${ }^{33}$.

Frantz Fanon, moins bien connu à la Martinique qu'ailleurs, examine en détail la question juive en parallèle avec la situation des Antillais dans Peau noire, masques blancs: cf. ses chapitres «Du prétendu complexe de dépendance du colonisé » et «L'expérience vécue du Noir ». Trois citations suffiront $\mathrm{ici}^{34}$ :

C'est mon professeur de philosophie, d'origine antillaise,

Qui me rappelait un jour : «Quand vous entendez dire du mal des Juifs, dressez l'oreille, on parle de vous ${ }^{35} »$.

L'antisémitisme me touche en pleine chair, je m'émeus, une

\footnotetext{
${ }^{32}$ Entretien du 16 octobre 2001.

${ }^{33}$ Henry-Valmore 1998. Le commentaire de cet écrivain et «ethno-analyste » antillais vaut la peine d'être cité : «Le symbole est roi. 'Oreilles de Juif, oreilles de noir'. Rencontre de deux mondes. Convergences de destins. Dans le miroir à deux faces la bonne image de soi a du mal à se fixer, déformée qu'elle est par la vision des autres, leur préjugés culturels et religieux et tous les mythes archaïques. Au regard de l'Occident chrétien, Juifs et Noirs tombent sous les coups de la même suspicion. Dans un cas comme dans l'autre l'inquiétante étrangeté fait la part belle au Diable » (p. 21).

${ }^{34}$ Cf. Miles 1997 pour une analyse plus complète de l'antisémitisme tel qu'il est traité par Frantz Fanon.

${ }^{35}$ Fanon, Peau noire, masques blancs, p. 98.
} 
contestation effroyable m'anémie, on me refuse la possibilité d'être un homme. Je ne puis me désolidariser du sort réservé à mon frère ${ }^{36}$.

Le Juif et moi : non content de me racialiser, par un coup heureux du sort, je m'humanisais. Je rejoignais le Juif, frère de malheur ${ }^{37}$.

L'on peut trouver une image beaucoup plus récente du Juif tel qu'il est représenté dans l'imaginaire antillais dans le second numéro de la revue, Portulan intitulé « Mémoire juive, mémoire noire. Deux figures du destin ». Comme l'annonçait l'éditeur dans l'avant-propos, le but était d'analyser le «paradoxe de la formation et de la persistante actualité du paradigme judéonègre de l'émancipation ${ }^{38}$. Parmi les 26 intellectuels ayant contribué à l'ouvrage, huit sont guadeloupéens ou martiniquais ${ }^{39}$. Comme thèmes de chapitre, l'on trouve : la lutte pour la liberté des Noirs et des Juifs au temps des Lumières (Joseph Jurt) ; sionisme et pan-africanisme (Abdoulaye Barro) ; et négritude et judéité (Maurice Dorès).

En dehors des cercles intellectuels, les sujets juifs ${ }^{40}$ attirent à peine l'attention générale ; la société juive locale n'est certainement pas un objet de discussion. Pour ceux qui en sont conscients, la communauté est perçue, à juste titre, comme extrêmement discrète (sinon fermée) et politiquement de droite, c'est-à-dire pro-Likoud. Celle-ci ne manifeste aucune velléité de rendre publiques ses propres positions sur le conflit arabo-israélien : les membres considèrent les médias français, et martiniquais par la même occasion, comme désespérément pro-palestiniens et anti-israéliens ${ }^{41}$.

\footnotetext{
${ }^{36}$ Ibid., p. 71

${ }^{37}$ Ibid., p. 98

${ }^{38}$ Toumson, p. 9.

${ }^{39}$ Deux des auteurs sont africains.

${ }^{40}$ L'exception serait le roman feuilleton intitulé Zielmann le Juif (dont l'action se déroule dans la France d'après-guerre) publié dans le seul journal quotidien de la Martinique, au long des trois premiers mois de l'année 2002. Cf. Dussauze, 2002.

${ }^{41}$ D'après le professeur B.I. Feldman, qui servait de consul honoraire d'Israël à la Martinique et fut son émissaire pour l'immigration à la Martinique de 1983 à 1988, cette peinture antiisraélienne dans les media est orchestrée depuis le Quai d'Orsay, par le ministère des Affaires étrangères. Le point de vue de l'Israélien Feldman représente un contrepoint intéressant par rapport au point de vue des Martiniquais sur les Juifs et sur Israël : «Comment les Antillais peuvent-ils se sortir [de leur malaise identitaire] ? En divorçant d'avec la France, en refusant l'influence de l'islamisme, en établissant des liens légitimes avec un autre peuple,
} 
Un article paru dans le magazine hebdomadaire à grande circulation du journal France-Antilles en mars 2002 atteste bien de la perception passéiste que les Martiniquais ont des Juifs : au milieu de remarques rudimentaires sur «les mélanges ethniques et la créolité de nos jours, » l'auteur évoque l'arrivée au dix-septième siècle des Juifs en provenance du Brésil et le rôle qu'ils ont joué dans l'installation des usines sucrières et l'introduction des techniques de raffinage. C'est "l'épopée de la canne à sucre, née en Inde, travaillée par les Arabes et répandue par le peuple juif, au cours de son long exode». Les descendants des Européens, des Africains, des Indiens, des Chinois («quand Confucius rencontre Descartes») et des Syriens ${ }^{42}$ sont tous représentés, mais l'article ignore complètement le fait qu'il y a toujours (ou à nouveau) des Juifs à la Martinique, regroupés autour d'un centre communautaire très bien organisé et un lieu de culte plutôt impressionnant.

On trouve exprimée une interprétation assez originale de l'histoire juive et de l'identité martiniquaise au cours d'un concert-colloque organisé par le mouvement rastafarien «One Love », le 21 mai 2002. L'événement, censé marquer le premier anniversaire de la reconnaissance officielle par la France de l'esclavage comme crime contre l'humanité, et promouvoir une campagne de réparation, était centré autour du discours du leader martiniquais de «One Love», Sékou Manga. Une grande partie de ce discours évoquant Israël - passé et présent - démontrait non seulement l'importance du rapport entre les Juifs et les Antillais mais aussi l'identité de destins qui les unissait. Les Africains, disait-il, sont les véritables héritiers du pacte de l'Ancien Testament passé entre les Hébreux et J(éov)ah.

En assimilant le transport des esclaves Africains aux Antilles à une « déportation », Manga établissait le rapprochement avec la déportation des Juifs au cours de la seconde Guerre Mondiale ; il rappelait que cette dernière représentait le précédent qui, en droit international, avait fait reconnaître la déportation comme un crime contre l'humanité et la création de l'actuel Etat d'Israël comme un modèle positif de réparation. «Il nous faut suivre la même logique... et demander les mêmes droits et les mêmes réparations ».

complémentaire, sensible lui aussi à la souffrance, qui a su trouver sa liberté, mais qui a besoin d'eux : le peuple juif ». Voir Feldman 2007.

${ }^{42}$ Pour une approche éclairée sur le sujet des prétendus Syriens, cf. Dubost 2000. 
Manga rappela à l'audience que les Juifs avaient été déportés non pas de Palestine mais d'Europe - en fait, bien avant les déportations nazies du vingtième siècle, les Romains, sous Titus, avaient opéré les leurs, au premier siècle. "N'avons-nous pas, nous aussi, le droit de réquisitionner notre propre terre, après cinq cents ans à peine ? » demanda-t-il à l'audience, provoquant un tollé d'applaudissements.

Ensuite, Manga évoqua la fatidique marque du pacte d'alliance : la circoncision. Pour lui, les ancêtres africains - même sans lien avec l'Ancien Testament - introduisirent ce signe d'alliance. «Qui est ce peuple - qui sont ces royaumes avec lesquels les alliances étaient consacrées par la circoncision ? » insistait-il en citant la Genèse.

En s'appuyant à la fois sur Hérodote et Arthur Koestler, Manga proclama que les ancêtres des Juifs actuels (européens) en Israël - les Scythes/Khazars - n'étaient pas circoncis. «L'histoire dit que le peuple qui se dit héritier de la circoncision ne l'est pas en fait». La circoncision est purement africaine - comme les Hébreux sont africains.

«Si de nos jours, Israël dirige les Etats-Unis et [leur] fait exécuter ses quatre volontés, c'est tout simplement parce que ce pays prétend être les enfants d'Abraham! » (immenses applaudissements). «Si ceux qui ne sont pas vraiment les enfants d'Abraham ont un tel pouvoir simplement en se prétendant tels, quel sera le pouvoir de ceux [les Africains] qui le sont vraiment?»

Les ancêtres de la Martinique, continuait Manga, sont venus de Canaan - pas le Canaan qui selon une croyance erronée recouvrirait l'Israël moderne et la Palestine, mais le «vrai » Canaan de l'Afrique de l'Est, du Centre et de l'Ouest. Le Congrès de Berlin qui, en 1885, partagea le continent en zones coloniales, avait en fait divisé Canaan ; et la France était un des principaux colonisateurs de Canaan. «Est-ce un hasard si la France est le premier pays à reconnaître le transport des esclaves comme crime contre l'humanité ? Quelle est la Providence divine dans cette histoire ? »

Il est difficile d'évaluer comment les quelques centaines de spectateurs présents au concert auront assimilé le message de One Love et sa version antillo-déconstructionniste de l'histoire juive. Toujours est-il que la moindre dose de rastafarisation sur l'île tendra à fausser la perception que les Martiniquais ont du judaïsme et de la communauté juive locale. 
Une autre image du judaïsme - plus érudite, mais tout aussi originale - est projetée à la Martinique par l'Ecole Kabbaliste de la Caraïbe, dont le doyen, A. D. Grad, enseigne la kabbale à une audience générale (c'est-à-dire non juive) depuis 1996. A. D. Grad, descendant direct (à la septième génération) du Gaon de Vilna, né en France de parents russes blancs en 1916, dispense un cours où les rudiments d'hébreu se combinent avec des éléments de philosophie «scientifique». Les classes hebdomadaires se tiennent le soir, dans les locaux de la librairie Annanda, au Lamentin. Elles attirent entre cinquante et soixante auditeurs fidèles, issus de toutes parts de la vie antillaise. Certaines sessions peuvent en attirer le double. Le kabbaliste refuse toute rémunération ou honoraire pour ses dialogues pédagogiques.

Un grand nombre de ses vingt-six publications - y compris $L a$ Kabbale Universelle, écrite spécifiquement pour une audience antillaise sont disponibles à la librairie Annanda qui se spécialise dans la vente de littérature religieuse, spirituelle et mystique de toutes sortes. Fondateur du Mouvement Kabbaliste Mondial (MKM- MAKOM) à Paris, en 1967, A.D. Grad est mondialement connu et a enseigné la philosophie à l'université du Chili et la psychologie à l'Institut pédagogique de Valparaiso. Selon lui, beaucoup d'Antillais ont une "sensibilité spéciale, une affinité avec les sources originales et solides de la vérité en dehors de l'Eglise et des sectes » comme il l'a exprimé au cours d'une entrevue personnelle avec l'auteur.

Il n'existe aucun lien entre l'Ecole kabbaliste de la Martinique et l'Association Cultuelle Israélite de la Martinique. En fait, le maître kabbaliste est à peine connu des membres de la communauté juive de la Martinique.

A mi-chemin, sur le plan théologique, entre le rastafarisme hébraïsant du Martiniquais Manga et le sionisme kabbaliste du Juif Grad, se trouve la Consolation d'Israël par les Iles de la Mer (actuellement inactive), la C.I.I.M., fondée par l'Antillais Dominique Bobi. La C.I.I.M. présente une rare combinaison d'anticolonialisme et de philosémitisme. Selon Bobi, la société martiniquaise demeure colonisée par un catholicisme antisémite tout autant que par l'assimilationnisme français. Les Juifs ont préservé leur identité à travers leur religion ancestrale et gagné leur émancipation politique à travers le sionisme. Ils devraient servir de modèle aux Antillais. Les deux peuples ont été victimes de l'esclavage et du racisme, mais seuls 
les Juifs ont trouvé une solution théo-politique adéquate (Feldman 2007 : 250-265).

Ces positions peu orthodoxes ont placé les membres de la C.I.I.M. dans une situation délicate vis-à-vis des éléments pro-français et propalestiniens de la société martiniquaise. Monsieur Bobi a décidé de s'installer en France métropolitaine en attendant de meilleurs auspices pour réactiver son organisation.

\section{Solidarité Martinique-Palestine et anti-sémitisme}

Les sentiments anti-israéliens, pro-palestiniens sont prédominants dans les cercles d'extrême gauche, pro-indépendantistes de la Martinique. Ils reposent en partie sur la popularité limitée dont jouit l'idée de la souveraineté pour l'île : la libération de la Palestine sert de substitut au combat pour l'indépendance à la Martinique. Exiger un état palestinien sert d'exutoire à ceux qui ne sont pas prêts à en forger un pour eux-mêmes. En ces temps de conflit intense au Moyen-Orient, les sentiments anti-israéliens rejoignent l'antisémitisme pur et simple comme il était particulièrement évident pendant les incursions israéliennes au Liban en 1980 et 2002 et lors de la seconde intifada de septembre 2000.

La première offensive militaire israélienne au Liban déclencha une série d'articles antisionistes dans Antilla, l'un des journaux à grande circulation de l'extrême gauche antillaise. Un bon nombre de ces articles (pour la plupart sous la plume d'un même individu, Pierre Davidas) ont clairement franchi le pas de l'antisionisme à l'antisémitisme. Le premier article intitulé « Israël, peuple et pays maudits » avançait que « tous ceux qui ont eu l'occasion de lire Mein Kampf doivent... reconnaître combien Hitler avait raison dans son jugement contre les Juifs $\gg^{43}$. A la requête de l'A.C.I.M., une action judiciaire fut intentée contre Davidas et Antilla pour diffamation et « incitation à la haine raciale ».

\footnotetext{
${ }^{43}$ Ces citations sont extraites de l'analyse approfondie de Giraud (1985). Giraud explique l'antisémitisme martiniquais en termes d'une paranoïa psychologique et politique résultant, chez une minorité de nationalistes et de politiciens de l'identité, de l'héritage d'un colonialisme répressif.
} 
Les intéressés répliquèrent en publiant de nouvelles attaques qui, cette fois-ci, associaient les Juifs du Moyen-Orient et les Juifs des Antilles. Les Juifs martiniquais étaient définis comme un « détachement du sionisme international ».

Aujourd'hui les Sépharades sionistes sont environ 400, mais quand ils seront 1000 ils domineront la Martinique, et nous mettront en esclavage chez nous ${ }^{44}$.

Les Juifs locaux, prétendait Davidas, ont déjà infiltré le gouvernement local et national ; ils contrôlent les compagnies de construction, d'assurance et de tourisme de l'île ; ils ont saboté un mouvement écologique pro-indépendantiste en plantant de la marijuana sur sa propriété et en faisant accuser l'un des ses membres de viol.

En 1983, la Cour de justice décida en faveur de l'A.C.I.M., imposa une amende aux accusés et les chargea des frais de procédure. Pour sa part, l'A.C.I.M. demanda une indemnité d'un franc - pour l'honneur.

Antilla est loin de représenter le sentiment des Antillais en général. L'on ne saurait trop répéter que la plupart des Martiniquais sont à peine conscients de la présence de Juifs dans la société de l'île. Le petit nombre de ceux qui le sont nourrissent à leur égard des sentiments plutôt positifs. Quand des actes de vandalisme dans le cimetière de Carpentras scandalisaient la France dans son ensemble en 1990, une manifestation spontanée se réunit devant la synagogue où l'on vit des Martiniquais faire parade de biens familiaux ornés de motifs juifs ${ }^{45}$.

Au moment où la seconde intifada faisait fureur, en 2000-2002, les medias Martiniquais étaient déjà effectivement mondialisés par l'intermédiaire de la télévision par satellite et par câble : le conflit israélopalestinien arrivait dans les foyers antillais comme jamais auparavant. Inévitablement cela affecta l'image générale du Juif. Pour mesurer l'importance de la seconde intifada sur la conscience antillaise, il est nécessaire de se reporter brièvement à la première Intifada de la fin des années 80 .

\footnotetext{
${ }^{44}$ Pierre Davidas, Antilla 55, 26 mai-2 juin 1983, p. 26.

${ }^{45}$ Entretien avec Didier Lévy, membre de l'A.C.I.M., 9 mai 2002. Monsieur Lévy, d'origine nord-africaine, a vécu à la Martinique pendant plus de vingt ans.
} 
En 1988 était créé le Collectif Martiniquais de Solidarité avec le Peuple Palestinien. Dans sa lettre à «la Communauté juive de Martinique », le Collectif (avec un homme d'affaires originaire de Ramallah à sa tête) soulignait que ses actions n'étaient pas dirigées contre les Juifs de l'île en tant qu'individus ou communauté, «ni contre le droit de l'Etat d'Israël à exister ». La lettre (qui ne reçut jamais de réponse) invitait la communauté à unir les forces «pour contribuer à la tâche urgente d'apporter la paix au Moyen-Orient en remplaçant la logique destructive de l'équilibre des pouvoirs par la logique du futur, du respect pour l'intérêt de tous » (lettre du 22 mars 1988).

Il apparaît que les membres du Collectif n'embrassaient pas tous cette position modérée telle qu'elle était officiellement articulée. Certains éléments extrémistes - principalement parmi les «anticoloniaux » antillais rejetaient le droit à l'existence même d'Israël et frôlaient la ligne de démarcation entre antisionisme et antisémitisme qu'Antilla avait incontestablement franchie. En conséquence, le Collectif se dissipa... jusqu'en juillet 2002, date à laquelle il réapparut, en réponse à la seconde intifada, sous le nom de Comité de Solidarité Martinique-Palestine pour une Paix Juste au Moyen-Orient (CSMP). Son président est maintenant l'écrivain antillais Daniel Boukman.

Le 6 avril 2002, à Fort-de-France, la journée de la Palestine fut organisée par le CSMP à la Maison de la Jeunesse et de la Culture du Lamentin. Le programme comprenait des exposés, des vidéos, de la poésie (arabe) et des danses folkloriques (martiniquaises). Une démonstration propalestinienne eut lieu le 6 avril 2002 à Fort-de-France, où l'on pouvait voir des placards (dont un avec une swastika) représentant le premier ministre israélien Ariel Sharon en nazi et l'assimilant à Hitler. Boukman, président du Comité, déclarait : «il y a une véritable émotion de la part de notre peuple qui ressent une grande injustice... le massacre, la destruction, le génocide va continuer contre les Palestiniens ». Parmi les groupes participant de manière très visible à cette démonstration se trouvait la Centrale Démocratique Martiniquaise des Travailleurs (CDMT). Quelques semaines auparavant, la section socio-médicale de la CDMT avait voté une motion «appel[ant] l'ensemble des Martiniquais à participer au mouvement international de solidarité avec le peuple palestinien ». Le rassemblement s'acheva avec la 
lecture, en créole, du «Discours sur le marché du chômage» du poète palestinien Samih El Qasim.

A la suite de la réoccupation de la Cisjordanie, les lettres à l'éditeur publiées dans France-Antilles (c'est-à-dire celles des 22-23 décembre 2001, du 23-24 mars, du 10 avril, du 11 avril, des 20-21 avril, du 29 mai , des 2223 juin 2002) étaient uniformément critiques à l'égard d'Israël, sans la moindre reconnaissance du suicide à la bombe qui avait précipité l'offensive israélienne. Vu l'importance du statut du personnage, les lettres du député à l'Assemblée nationale ${ }^{46}$, Camille Darsières, valent la peine d'être citées.

Dans une lettre ouverte au premier ministre d'alors, Lionel Jospin, reproduite dans le France-Antilles du 28 décembre 2001, Darsières reproche au gouvernement français de ne pas faire plus grande pression sur Israël :

Je suis de ces nombreux citoyens de l'outre-mer français que l'Histoire a sensibilisés à la lutte des peuples pour leur émancipation, qui souhaitent de la France des Droits de l'Homme une position claire, se désolidarisant d'avec le lâche abandon des valeurs universelles en lequel se vautrent de grandes puissances.

Pour ce représentant au Parlement français, tous les actes de militantisme palestiniens constituent «une résistance légitime... à l'occupation [qui] ne saurait être assimilée au terrorisme ».

Trois mois et demi plus tard, à la suite des bombes incendiaires et autres actes de vandalisme contre des synagogues en France métropolitaine, Darsières, dans une lettre publiée dans les colonnes du France-Antilles du 18 avril 2002, écrivait :

[N]ous n'approuvons pas ces attentats... contre les Synagogues... nous ne les condamnerons expressément que lorsque les associations juives, de France et d'ailleurs, auront expressément condamné l'Etat d'Israël pour ne pas respecter les résolutions de l'O.N.U., notamment celles l'invitant depuis 1967, à évacuer les territoires palestiniens qu'il a occupés.

\footnotetext{
${ }^{46}$ La Martinique envoie quatre représentants à l'Assemblée nationale. Darsières avait été élu sur le programme du Parti Progressiste Martiniquais (PPM), fondé par Aimé Césaire.
} 
A aucun moment, il faut le noter ici, la synagogue de Martinique (à son ancienne ou à sa nouvelle adresse) n'a été la cible de vandalisme d'inspiration religieuse ou politique, ou de graffiti anti-sémites.

Or, il se trouve que la seconde intifada coïncida avec un événement politique de première importance au niveau local : le Congrès des élus départementaux et régionaux de 2002 qui rassembla les représentants élus pour discuter du futur statut de la Martinique vis-à-vis de la France et pour proposer une reformulation du gouvernement local. L'une des motions les plus chaudement contestée fut celle relative à reconnaissance de la nation martiniquaise. En faveur de cette motion, il est à noter cette déclaration de Louis Boutrin, du parti Bâtir le Pays Martinique (B.P.M.) :

Il n'y a qu'un seul peuple... qui ne constitue pas une nation, tout en habitant son propre pays. C'est le peuple palestinien. J'espère, chers Collègues, que vous n'allez pas nous assimiler avec les Palestiniens.

Congrès de la Martinique, 20 février, 2002 (émission télévisée de Radio France Outre-mer [RFO]).

Il est impossible de mesurer l'influence que peut avoir l'opinion des élites sur les masses populaires qui, de manière générale, portent peu d'intérêt aux sujets de politique internationale (sauf, bien entendu, ceux qui concernent la France). Il ne fait aucun doute, cependant, qu'en ce qui concerne l'intelligentsia et les chefs politiques martiniquais, la politique sécuritaire de Sharon et Olmert - qui, en tant que représentants élus, incarnent, qu'ils le veuillent ou non, l'Etat juif - a réduit le peu de philosémitisme ${ }^{47}$ que la Shoah avait fait naître dans le monde francophone. Etant donné que la communauté juive de Martinique n'élève aucune protestation publique lorsqu'Israël est attaqué, l'image déjà floue du Juif martiniquais - «l'errant » toujours silencieux, citoyen visible mais étranger social - reste trouble.

${ }^{47} \mathrm{Cf}$. la seconde citation en tête de ce chapitre. 


\section{Conclusion : la mentalité errante du Juif antillais}

Le titre d'un documentaire de la télévision française sur l'inauguration, en 1996, de la synagogue «du bout du monde» à la Martinique joue sur les mots : Antilles sémites comme un écho d'antisémite ${ }^{48}$. Un tel jeu de mots est acceptable dans la mesure où les Juifs vivent librement à la Martinique et les expressions royalistes, vichystes et pro-palestiniennes d'antisémitisme sont ou bien dépassées ou bien marginales. Durant quatre-cents ans, les Juifs se sont périodiquement installés sur l'île, ballotés entre des périodes d'expulsion (du Brésil, en 1654 et de la Martinique, en 1683), de catastrophe naturelle (les années précédant l'éruption volcanique de la Pelée en 1902) et de pures persécutions (le régime local de Vichy de 1940 à 1943). De nos jours, les gendarmes français sont postés en face du centre communautaire juif lors des grandes fêtes et autres grands rassemblements (comme pour la célébration de l'indépendance d'Israël), non pas pour intimider la communauté mais pour la protéger ; de même, un agent des Services secrets maintient le contact avec eux, non pas pour épier mais pour rassurer. Plus qu'à aucun moment de l'histoire, les Juifs de l'île ont la possibilité de sortir de leur propre marronnage et hyperdiscrétion religieuse et prendre leur place dans le fameux «melting pot» martiniquais. La rencontre publique en juillet 2008 du Grand rabbin du Consistoire central de France, René Samuel Sirrat, avec le prêtre de la paroisse de Bellevue, Hugues Lafine, en est peut-être un bon signe.

Cependant cela ressemble peu au Juif martiniquais de planter fermement ses racines sur l'île. Rare est le Juif pour qui ce département français pourra jamais être un foyer véritable et permanent : rare est le Juif qui se fasse enterrer sur l'île. Est-ce parce que dans l'héritage de l'assimilation coloniale (et catholique) entre aussi l'antisémitisme français, sous ses formes à la fois pseudo-intellectuelles et religieuses ? Est-ce à cause de la liturgie juive elle-même - qui lui enjoint de rester « une nation à part » - qu'il se voit mal intégrer une culture d'hybridité, de métissage et de créolité ?

Les Juifs martiniquais sont ou bien «de passage »- même si le passage dure des décennies - ou se dissolvent dans le paysage culturel.

${ }^{48}$ Cf. Esbete 1996. 
Comme le poisson local qui porte leur nom ${ }^{49}$, les Juifs frétillent dans les eaux du pays mais ne figurent jamais au menu martiniquais. Partir et revenir, tel a été le lot du Juif martiniquais. Ou, pour invoquer Aimé Césaire dans son Cahier d'un retour au pays natal,

Partir.

Comme il y a des hommes-hyènes et des

hommes-panthères, je serais un homme-juif...

\section{REFERENCES}

Achéen, René and Fitz A. Baptiste. 1979. «La Martinique sous l'amiral Robert»(tome 2). Les Cahiers du Centre d'Etudes Régionales AntillesGuyane, $\mathrm{n}^{\circ} 37$.

Anderson, Benedict. 1983. Imagined Communities. Reflections on the Origin and Spread of Nationalism. Londres : Verso.

Arbell, Mordechai. Spanish and Portuguese Jews in the Caribbean and the Guianas. A Bibliography (1999) (chapitre 10, «Haiti, Martinique, Guadeloupe »). Providence, Rhode Island : Bibliothèque John Carter Brown.

Bernabé, Jean, Patrick Chamoiseau et Raphaël Confiant. 1989. Eloge de la créolité. Paris : Gallimard Presses Universitaires Créoles.

Bruneau-Latouche, Eugène et Philippe Cordiez. 2002. 209 Anciennes familles subsistantes de la Martinique. Aix-en-Provence, Fort-de-France, Paris.

Burton, Richard D.E. et Camille Chauvet. 1978. La Martinique sous l'amiral Robert (vol. 1). Les Cahiers du Centre d'Etudes Régionales Antilles-Guyane, $\mathrm{n}^{\circ} 34$.

Cahen, Ab. 1881-2. «Les Juifs de la Martinique au XVII ${ }^{\mathrm{e}}$ siècle ». Revue d'Etudes Juives, vol. 2-5.

\footnotetext{
${ }^{49}$ Poisson nocturne dont le nom zoologique est Priacanthus (de l'ordre des Percifornes).
} 
Césaire, Aimé. 1947. Cahier du retour au pays natal. Paris : Présence Africaine.

Césaire, Aimé. 1976. Aimé Césaire: oeuvres complètes, vol. 3, Oeuvre historique et politique: discours et communications. Paris : Editions Désormeaux.

Césaire, Aimé. 2001. Entretien avec l'auteur (16 octobre).

Césaire, Aimé. 2002. Entretien avec l'auteur (25 avril).

Chauleau, Liliane. 1990. « Départements d'outre-mer. » In : Gildas Bernard, Les Familles Juives en France: XVI e siècle - 1815. Paris : Archives nationales.

Comité solidarité Martinique-Palestine pour une paix juste au Moyen-Orient. Mars 2002. Echos de Palestine. Fort-de-France.

Dubost, Isabelle. 2000. «Les 'Syriens' Martiniquais : une alternative identitaire exemplaire». In : Jean Bernabé et. al. (eds.), Au visiteur lumineux : des îles créoles aux sociétés plurielles. Petit Bourg, Guadeloupe : Ibis Rouge Editions.

Dussauze, Michel. 2002 (roman feuilleton 28 janvier-30 mars). Zielmann le Juif.

France-Antilles (Fort-de-France, Martinique).

Esbete, José. 1996. L'Emission hébraïque (programme hebdomadaire), TFI.

Fanon, Frantz. 1952. Peau noire, masques blancs. Paris : Editions du Seuil.

Feldman, Israël. 2007. La deuxième étape du sionisme : justice restauratrice. Dijon-Quetigny : Epem Tradition.

Feldman, Israël. L'Ile Aux Fleurs ou la dernière colonie, à paraître.

France-Antilles. Le quotidien d'information des Antilles. 1996 (February 28). «La communauté juive a son lieu de culte», p. 1-7.

France-Antilles. Le quotidien d'information des Antilles. 1996. (4 mai). «Les mystères de l'écriture sacrée », p. 7.

France-Antilles. Le quotidien d'information des Antilles. 2002 (2 avril). «Motion sur la situation en Palestine». 
France-Antilles. Le quotidien d'information des Antilles. 2002 (6-7 avril). «A propos de la Manifestation de solidarité avec le peuple palestinien ».

France-Antilles. Le quotidien d'information des Antilles. 2002 (8 avril). «En solidarité avec la Palestine... »

France-Antilles Magazine. 2002 (semaine du 9-15 mars). «Les marques d'un brassage ethnique », p. 6-8, 10, 12.

Giraud, Michel. 1985. "Crispation identitaire et antisémitisme en Martinique : le cas d' 'Antilla' », Traces, 1985, n¹1, p. 129-151.

Giraud, Michel. 2000. « Après la colonie, la nation? Le devenir politique des départements français d'Amérique en question », Pouvoirs dans la Carä̈be (PDLC), n 12 , p. 79-109.

Giraud, Michel. 2007. «L'arbre et la forêt : a propos de quelques polémiques récentes », Esprit, n³32, p. 81-83.

Grad, A. D. 1994. La Kabbale universelle. Monaco : Editions du Rocher.

Grad, A. D. 2002. Entretien avec l'auteur (21 juin).

Henry-Valmore, Simone. 1998. «Oreilles de Juif, Oreilles de Noir.»In : «Portulan. Mémoire juive, mémoire nègre. Deux figures du destin» Châteauneuf-le-Rouge : Vents des Îles.

Jennings, Eric T. 2000. «La dissidence aux Antilles (1940-1943).» Vingtième Siècle. Revue d'histoire, nº6, p. 55-71.

Jennings, Eric T. 2002. «Last Exit from Vichy France : The Martinique Escape Route and the Ambiguities of Emigration. » The Journal of Modern History, ${ }^{\circ} 74$, p. 289-324.

Léotin, Marie-Hélène. 1993. La Martinique pendant la seconde Guerre Mondiale, 1939-1945. Centre Régional de Documenation Pédagogique des Antilles et de la Guyane.

Loker, Zvi. 1991. Jews in the Caribbean. Evidence on the History of the Jews in the Caribbean Zone in Colonial Times. Jerusalem : Institute for Research on the Sephardi and Oriental Jewish Heritage.

Louis, Patrice. 2006. «Raphaël Confiant et les «Innommables»». Le Monde, 2 décembre, p. 3. 
Miles, William F.S. 1986 (février). «The Jews of Martinique ». Midstream, p. 31-33.

Miles, William F.S. 1992. Paradoxe au paradis : de la politique à la Martinique. Paris : l'Harmattan.

Miles, William F.S. 1997. « Negritude and Judaism. » The Western Journal of Black Studies, 21:2, p. 99-105.

Miles, William F.S. 2003. "Aimé Césaire and My Jewish Question.» Wadabagei. A Journal of the Caribbean and Its Diaspora, nº, p. 171-182.

Petitjean-Roget, Jacques. 1956. «Les Juifs à la Martinique sous l'Ancien Régime. » Revue d'Histoire des Colonies, n43, p. 138-58.

Petitjean-Roget, Jacques et Eugène Bruneau-Latouche. 1983. Personnes et Familles à la Martinique au XVII siècle (2 volumes). Fort-de-France : Société d'Histoire de la Martinique.

Riboh, Amram. 5762 (Nissan ; équivalent de mars 2002). «Les Juifs de la Martinique », Kenaf Haaretz. Le Journal de la Communauté Juive de la Martinique (5), p. 4.

Robert, Georges. 1950. La France aux Antilles. Paris : Librairie Plon.

Roth, Cecil. 1932. Histoire des Marranes. Paris : Collections Histoire.

Sala-Molins, Louis. 1987. Le Code noir ou le calvaire de Canaan. Paris : Presses Universitaires de Paris.

Suvélor, Roland. 1983. «Première déclaration sur un 'nouveau' racisme ». Antilla, n69 (16-23 septembre), p. 46-47.

Zizine, Pierre. 1947. L'amiral Robert devant La Haute Cour. Paris : Imp. Emmanuel Pourtout. 


\title{
RESUME
}

\section{La créolité et les Juifs de la Martinique}

L'affaire Dieudonné-Confiant de juin 2005 est révélatrice d'une ambiguïté dans le discours de la créolité à la Martinique: d'un côté, la volonté d'assumer entièrement l'éventail des différents composants ethniques de son passé (et non seulement l'héritage africain de la négritude) ; d'un autre côté, la non-reconnaissance de son constituant juif rétabli en son sein. De l'Ancien Régime jusqu'à l'installation de l'Association Cultuelle Israélite de la Martinique (A.C.I.M.) dans les années 1970, les Juifs ont vécu le refuge, l'expulsion, la persécution, et le renouveau. L'attitude à l'égard du Juif dans la société martiniquaise contemporaine est mitigée, allant de la critique acerbe liée aux intifadas à la sympathie de certains comme Aimé Césaire. Tant que la Martinique ne considérera pas la communauté juive comme une couche intégrante de son multiculturalisme identitaire, tant que les Juifs euxmêmes ne surmonteront pas leur réticence à assumer la réalité de leur présence géographique, la créolité martiniquaise tant claironnée restera incomplète.

\begin{abstract}
Caribbean hybridity and the Jews of Martinique

In 2005-6 controversy broke out in Martinique and France when a French West Indian author of note came to the defense of an Afro-French comedian accused of anti-Semitism. The matter brought to the fore an ambiguity within the discourse of créolité. On the one hand, créolistes claim to embrace the entire ethnic gamut of Martinique's past to construct an inclusive and unique identity (and not one based principally on the African heritage, as with négritude). On the other hand, there is reluctance to accept the Jewish component that has reestablished itself on the island. From the Ancien Régime to the formation of the Martinican Jewish community center in the 1970s, Jews have experienced asylum, expulsion, persecution, and revival. Perceptions of the Jew in Martinican society are mixed, ranging from criticism triggered by the Intifadas to sympathy expressed by Aimé Césaire
\end{abstract}


and others. Until Martinique assumes the Jewish community within her sense of multicultural identity, and the Jews themselves overcome their reticence to assume their geographical presence, the much-heralded creolite of Martinique will remain incomplete. 